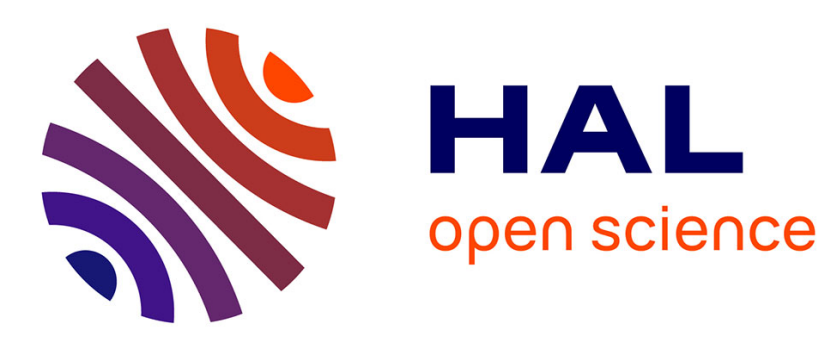

\title{
Enlargement and the EU Periphery: The Impact of Changing Market Potential
}

\author{
Marius Brülhart, Matthieu Crozet, Pamina Koenig
}

\section{To cite this version:}

Marius Brülhart, Matthieu Crozet, Pamina Koenig. Enlargement and the EU Periphery: The Impact of Changing Market Potential. The World Economy, 2004, 27 (6), pp.853-875. halshs-00096285

\section{HAL Id: halshs-00096285 \\ https://shs.hal.science/halshs-00096285}

Submitted on 19 Sep 2006

HAL is a multi-disciplinary open access archive for the deposit and dissemination of scientific research documents, whether they are published or not. The documents may come from teaching and research institutions in France or abroad, or from public or private research centers.
L'archive ouverte pluridisciplinaire HAL, est destinée au dépôt et à la diffusion de documents scientifiques de niveau recherche, publiés ou non, émanant des établissements d'enseignement et de recherche français ou étrangers, des laboratoires publics ou privés. 


\title{
Enlargement and the EU Periphery: The Impact of Changing Market Potential *

\author{
Marius Brülhart ${ }^{\dagger} \quad$ Matthieu Crozet $^{\ddagger} \quad$ Pamina Koenig ${ }^{\S}$
}

this version: February 2, 2004

\begin{abstract}
We study the impact of changing relative market access in an enlarged EU on the economies of incumbent Objective 1 regions. First, we track the impact of external opening on internal spatial configurations in a three-region economic geography model. External opening gives rise to potentially offsetting economic forces, but for most parameter configurations it is found to raise the locational attractiveness of the region that is close to the external market. Then, we explore the relation between market access and economic activity empirically, using data for European regions, and we simulate the impact of EU enlargement on Objective 1 regions. Our predicted market-access induced gains in regional GDP and manufacturing employment are up to seven times larger in regions proximate to the new accession countries than in "interior" EU regions. We also find that a future Balkans enlargement could be particularly effective in reducing economic inequalities among the EU periphery, due to the positive impact on relative market access of Greek regions.
\end{abstract}

${ }^{*}$ We thank Carsten Schürmann, Roman Römisch and Peter Huber for the generous provision of data. ${ }^{\dagger}$ DEEP-HEC, University of Lausanne

${ }^{\ddagger}$ TEAM-University of Paris I

${ }^{\S}$ CREST and University of Paris I 


\section{Introduction}

Europe's economic centre of gravity is shifting east. No event marks this tendency more visibly than the 2004 EU enlargement, which integrates eight Central and Eastern European countries (CEECs) fully into the EU's internal market. Improved access to and from the CEEC economies is likely to affect production structures not just in the affected new member states but also in incumbent EU countries.

One can think of a myriad economic mechanisms through which EU enlargement may affect the economies of Western Europe: increased specialisation according to comparative advantage, enhanced scope for scale economies in a larger European market, changing factor supplies through movements of workers and capital, stiffer competition from CEEC competitor firms, to name but the most obvious. ${ }^{1}$ We focus on a particular aspect of this complex set of economic effects, the locational implications of a changing spatial configuration of market access at the level of sub-national EU regions. We abstract from endowment differences and market structure and ask how the changes in relative market access are likely to affect peripheral regions of pre-enlargement member states, all else equal.

We first explore this issue in a three-region new economic geography model. Except for differences in trade costs, space is assumed to be homogenous, and sectoral location is determined endogenously through the interplay of agglomeration and dispersion forces. Two of the three regions are relatively integrated (the "EU"), and we track how the economies of these regions are affected by an opening towards the third region (the "CEECs"). External market opening affects several spatial forces. Forces related to better access to foreign export markets and cheaper imports enhance the locational attraction of the border region. Conversely, forces related to import competition from foreign firms enhance the locational attraction of the interior region.

The interplay of these forces in the nonlinear setup of the model can lead to a variety of equilibria. We find that, for most parameter configurations, external liberalisation favours the concentration of the mobile sector in the region that is closer to the outside country (the "border region"). However, this mechanism is not deterministic. For example, a sufficiently strong pre-liberalisation concentration of economic activity in the region that is relatively remote from the outside country (the interior region) can make this concentration globally stable, i.e. the locational forces triggered by the external opening are insufficient to offset the locational

\footnotetext{
${ }^{1}$ For simulations of country-level economic effects from eastward EU enlargement based on fully specified computable general equilibrium models, see Baldwin, Fancois and Portes (1997), Bröcker (1998) and Forslid, Haaland, Midelfart-Knarvik and Maestad (2002).
} 
hysteresis of an established agglomeration. For some parameter values the model can even predict a locational pull towards the interior region (e.g. when the relative size of the mobile sector is small).

In our empirical analysis we seek to capture the essential features of the theoretical framework without attempting full structural estimation of the model. Our main explanatory variable is market potential, an inversely distance-weighted average of the economic mass of all European regions, calculcated individually for each region. We apply an economically relevant measure of interregional distance by drawing on a set of bilateral estimates of average road freight travel time. For the economic mass variable we use alternatively regional purchasing-power parity GDPs, and regional employment in particular sectors (which yields "sectoral market potentials").

The market potential measures are the main ingredient to the two stages of our empirical exercise. First, we estimate the relation between, on the one hand, regional per-capita GDP and regional manufacturing employment, and, on the other hand, computed regional market potentials for the full sample of up to 202 European regions. ${ }^{2}$ In the second stage, we take the estimated first-stage coefficients to simulate the effect of changes in regional market potentials. The scenario we simulate is stark. We compare a situation where the EU ends at its pre-2004 eastern border (i.e. where market potentials take account only of regions in incumbent member countries) with a situation where the EU has grown to encompass 25 or even 33 countries (i.e. where market potentials incorporate also the ten 2004 accession countries, and eight potential future members in South-Eastern Europe). These simulations thus provide upper-bound estimates of the pure market-potential effects of EU enlargement on incumbent regions.

Our simulations suggest that the effects on per capita incomes of Objective 1 regions are small, with an estimated average gain from the 2004 enlargement of 0.93 percent, compared to 0.65 percent for the non-Objective 1 regions. Large magnitudes, however, are found for effects on manufacturing, the most footloose of broad sectors. Manufacturing employment as a share of population is predicted by our simulations to expand by 33 percent in Objective 1 regions on average. This number is surely too high to be plausible, and thus highlights the limits of our methodology, but it is interesting that we find no region for which our simulations suggest a negative impact of enlargement on manufacturing employment. We also detect significant variance across Objective 1 regions: the enlargement-induced boost to manufacturing of the

\footnotetext{
${ }^{2}$ Niebuhr (2003) has estimated a similar model for EU+EFTA regions, using average wages as the dependent variable.
} 
most affected region (Burgenland, Austria) is seven times larger than that of the least affected region (South Yorkshire, UK).

The paper is structured as follows. Section 2 describes the theoretical model (with the main algebraic elements given in Appendix A), and Section 3 presents our empirical results. Section 4 concludes.

\section{External Market Access and Internal Geography: A Three- Region Model}

We develop a three-region version of Krugman's (1991) seminal core-periphery model, in order to study the impact of improved external market access on the internal geography of a trading bloc. By adopting this framework, we consciously abstract from locational features other than spatial demand linkages: since regions are assumed to be identical in terms of technologies, endowments and tastes, we ignore a large and important literature on integration effects other than the market-size linkages that we study here. We do not claim, therefore, to provide a comprehensive account of locational changes that might be triggered by EU enlargement. Rather, we want to focus on the main forces identified by the modern economic geography literature and to explore them in terms of their implications for the EU periphery as the EU is being enlarged eastwards.

We confine the exposition of the model in this section to a rough sketch of the main features and some salient simulations. A detailed exposition of the analytical framework is given in Appendix A.

\subsection{Symmetric Regions: Endogenous Agglomeration}

\subsubsection{The Basic Model}

Consider two countries: a domestic country, which in turn contains two regions, labelled 1 and 2; and a foreign country, labelled 0 . We think of the domestic country as the EU, and of the foreign country as the accession countries. The two regions of the domestic country will stand for the EU's border and interior regions, relative to the eastern accession countries.

There are two sectors: monopolistically competitive "manufacturing", which produces a differentiated good and stands for all increasing-returns and mobile production activities in the economy; and "agriculture", the perfectly competitive immobile sector. Each of the two production factors is specific to one sector ("workers" and "farmers"). All goods are traded 
among all regions.

The size and composition of the foreign economy is assumed to be fully exogenous. It contains $L_{A 0}$ agricultural workers and $L_{0}$ manufacturing workers, which are all immobile. In the domestic country, regional supply of agricultural labour is fixed: the two domestic regions contain respectively $L_{A 1}$ and $L_{A 2}$ immobile farmers. In domestic manufacturing, however, only the total amount of manufacturing labour is fixed: the country has $L$ manufacturing workers, distributed endogenously among regions: $L=L_{1}+L_{2}$. Workers migrate between regions 1 and 2 according to the real wage difference. Following standard practice and without loss of generality, we normalise the number of domestic manufacturing workers, $L=1$. The regional shares of workers can then be expressed as $L_{1}=\lambda$ and $L_{2}=1-\lambda$.

Product markets of the three regions are separated by trade costs. Manufacturing varieties produced in region $r$ are sold by firms at mill price, and the entire transaction cost is borne by consumers. This is because trade costs are of the "iceberg" type: when one unit is shipped, priced $p$, only $1 / T$ actually arrives at destination. Therefore, in order for one unit to arrive, $T$ units have to be shipped, increasing the price of the unit received to $p T$. Trade in manufactured goods is subject to such trade costs, which differ across regions. $T_{12}$ is the internal trade cost, which applies to interregional domestic trade (with $T_{12}=T_{21}$ ). $T_{01}$ and $T_{02}$ are the trade costs that arise in each domestic region's trade with the outside economy. To begin with, we assume $T_{01}$ and $T_{02}$ to be equal, and the two domestic regions therefore to be perfectly symmetric. This assumption will later be relaxed.

The agricultural good is assumed to be traded at zero cost, both interregionally and internationally. Therefore, its price equalises everywhere: $p_{A 1}=p_{A 2}=p_{A 0}$. We choose units such that $p_{A}=w_{A}$ in each region. Finally, we use the agricultural good as a numéraire, therefore $w_{A}=1$ in each region.

\subsubsection{External Trade Liberalisation and Internal Geography}

What happens to the domestic distribution of manufacturing activity as external trade barriers are lowered? A decrease in the external trade cost triggers two forces. On the one hand, cheaper access to the exterior market lowers the incentive for domestic firms to locate near domestic consumers, which now represent a smaller share of domestic firms' sales. Thus, the domestic demand-related agglomeration force is weakened by the increased importance of foreign 
demand.$^{3}$ For similar reasons, the domestic cost-related agglomeration force is weakened by the increased importance of foreign supply: foreign firms now represent a more important share of supply to domestic consumers. ${ }^{4}$

On the other hand, trade liberalisation also affects the intensity of competition in the domestic country. Increased competition from foreign firms reduces the relative importance for domestic firms of locating away from domestic competitors, and thus attenuates dispersion forces. ${ }^{5}$

Simulations show that, while external liberalisation decreases both internal agglomeration and dispersion forces, the effect on the dispersion force generally dominates. ${ }^{6}$ As a result, the range of parameter values for which domestic manufacturing agglomerates in only one region decreases in the level of external trade costs. Given the perfect symmetry of domestic regions, the location of such agglomerations is indeterminate. The same result obtains if we hold external trade costs constant but let the foreign country get bigger: the larger the outside economy, ceteris paribus, the greater the probability that domestic manufacturing agglomerates in one region. The prediction from the model with symmetric domestic regions is clear-cut: closer economic integration with the external country favours the concentration of domestic manufacturing activity. ${ }^{7}$

\subsection{Asymmetric Regions: Changing Relative Attractiveness of Border and Interior Regions}

Perfect symmetry of domestic regions is of course a highly unrealistic assumption, and one that fits badly with our aim to shed light on differential impacts of enlargement across EU regions. We therefore now allow the two external trade costs to differ. Specifically, we suppose that domestic region 2 has better access to the foreign market, such that $T_{02}<T_{01}$. Hence, we call region 2 the border region, while we refer to region 1 as the interior region.

\footnotetext{
${ }^{3}$ In Appendix equations (15) and (16), income from the foreign country becomes a more important part of total demand.

${ }^{4}$ In Appendix equations (18), (19) and (20), an increased presence of the foreign firms now constitutes the main element that drives down price indices.

${ }^{5}$ In Appendix equations (18), (19) and (20), as stated before, an increased presence of foreign firms lowers both price indices, which in turn lowers $w_{1}$ and $w_{2}$.

${ }^{6}$ Simulation results can be provided on request.

${ }^{7}$ The same qualitative result has been found in related models by Monfort and Nicolini (2000) and Paluzie (2001). Krugman and Livas Elizondo (1996) show that this result is reversed if the domestic dispersion force is assumed to be exogenous and independent of trade costs: in that case external liberalisation favours internal dispersion. The same qualitative result is obtained by Behrens, Gaigné, Ottaviano and Thisse (2003), internal dispersion arises through intensified endogenous internal competition effects.
} 


\subsubsection{Trade Liberalisation}

Our simulations reveal two particular features of the asymmetric setup. First, as foreign demand weakens the domestic agglomeration force, an additional effect appears, because domestic firms now have an incentive to locate in the region closest to the foreign market. One of the potential effects of trade liberalization is thus to attract domestic firms towards the border, where they can reap the full benefit of improved access to foreign demand. Second, as foreign supply weakens the domestic dispersion force, the interior region allows firms to locate away from the foreign competitors. Hence, trade liberalisation may attract domestic firms towards the interior region, where they are relatively sheltered from foreign competition.

Figure 1: Internal Geography and External Openness

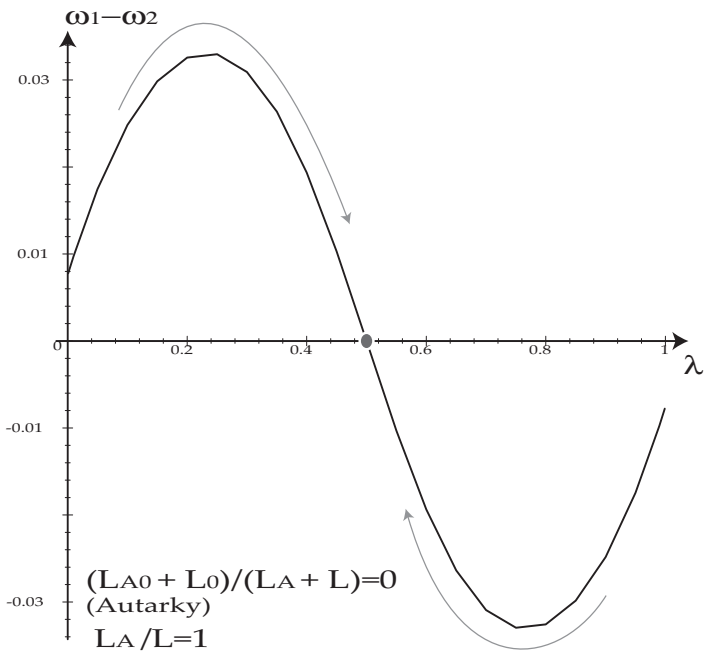

(a)

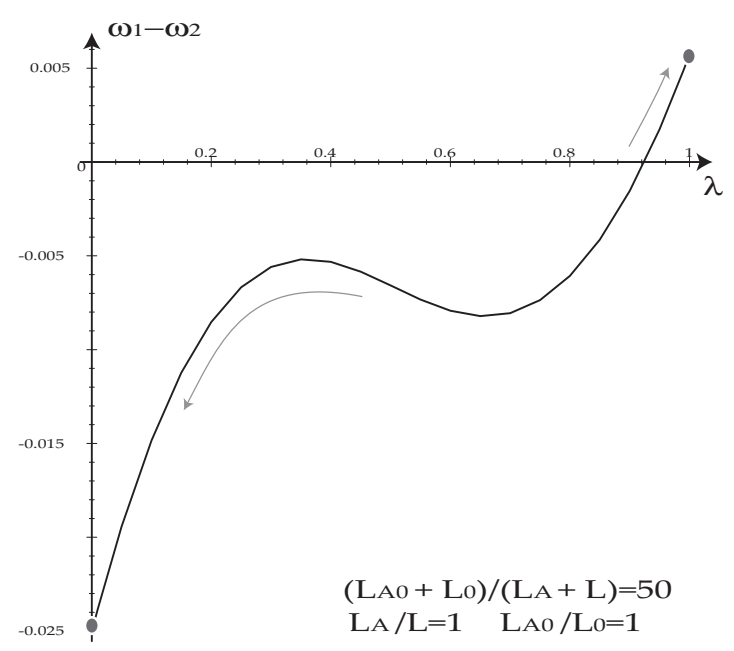

(b)

Figure (1) illustrates the impact of these forces according to the degree of trade liberalisation. It plots real-wage differences between the two domestic regions $\left(\omega_{1}-\omega_{2}\right)$ against the share of manufacturing that locates in the interior region $(\lambda){ }^{8}$ An allocation of manufacturing is an equilibrium either when real wages are equalised, or when manufacturing is totally agglomerated in one region and the (potential) real wage in the other region is lower. In Figure (1a), the domestic country is in autarky, and the dispersed configuration turns out to be the only stable

\footnotetext{
${ }^{8}$ Specifically, for given values of $T_{01}$ and $T_{02}$, we numerically solve for $w_{1}$ and $w_{2}$ over a range of values of $\lambda \in(0,1)$. We then substitute the obtained $w_{1}$ and $w_{2}$ into $\Delta \omega$ to plot the real-wage curves. Fig (a) is drawn with $T_{01}=5.3$ and $T_{02}=3.6$. The values of the other parameters are: $\sigma=4, \beta=3 / 4, \mu=0.4, \alpha=0.25$, $T_{12}=2.4$.
} 
equilibrium. ${ }^{9}$. In Figure (1b), the domestic country trades costlessly with a large foreign country. The curve tracing relative real wages has shifted to the right and pivoted anti-clockwise: in Figure (1b), the curve now comes to cross the $x$ axis with a positive slope, meaning that only the two completely agglomerated configurations are stable equilibria. For this configuration, we thus find that liberalising trade with the outside world will enhance the relative locational attraction of the border region. The increase of demand emanating from the foreign country dominates the competition effect of proximity to foreign firms, and domestic manufacturing is attracted to the border region. Agglomeration of industry in the interior region remains possible, however, but only if, before liberalisation, that region has hosted a disproportionately large share of domestic manufacturing (around 92 percent in the case of Figure (1b)).

\subsubsection{Sectoral Composition of the Foreign Economy}

We now consider the implications of varying the sectoral composition of of the outside economy. In Figure (2a), the foreign country is specialised in agriculture, while the domestic economy has equal amounts of farmers and manufacturing workers. Farmers represent an immobile workforce and thus a large additional demand without additional competition force. What we see in Figure (2a) is therefore the result of an increase in the locational attractiveness of the border region subsequent to trade liberalization. When foreign markets represent larger demand rather than fiercer competition, integration will favour manufacturing relocation towards the border region.

Conversely, Figure (2b) depicts the case where manufacturing accounts for a bigger share of labour abroad than at home. The competition effect of lower trade costs with the foreign country therefore becomes relatively more important, and the forces for agglomeration in the border region are attenuated. Specifically, in the scenario illustrated in Figure (2b), the basin of attraction of border-region agglomeration is considerably smaller compared to the scenario of Figure (2a), and a partially dispersed equilibrium with $\lambda=0.6$ becomes locally stable.

\subsubsection{Sectoral Composition of the Domestic Economy}

Finally, we investigate the importance of the home country's sectoral composition for the forces that shape the spatial distribution of economic activity. Figure (3) features (a) a home country that hosts more agriculture than industry $\left(L_{A} / L=1.2\right)$ and (b) a home country that hosts more industry than agriculture $\left(L_{A} / L=0.8\right)$.

\footnotetext{
${ }^{9}$ Figure (1) is drawn for a value of $T_{12}$ for which industry is dispersed in autarky $\left(T_{01}=T_{02}=\infty\right)$
} 
Figure 2: Internal Geography and Sectoral Specialisation of the Foreign Economy

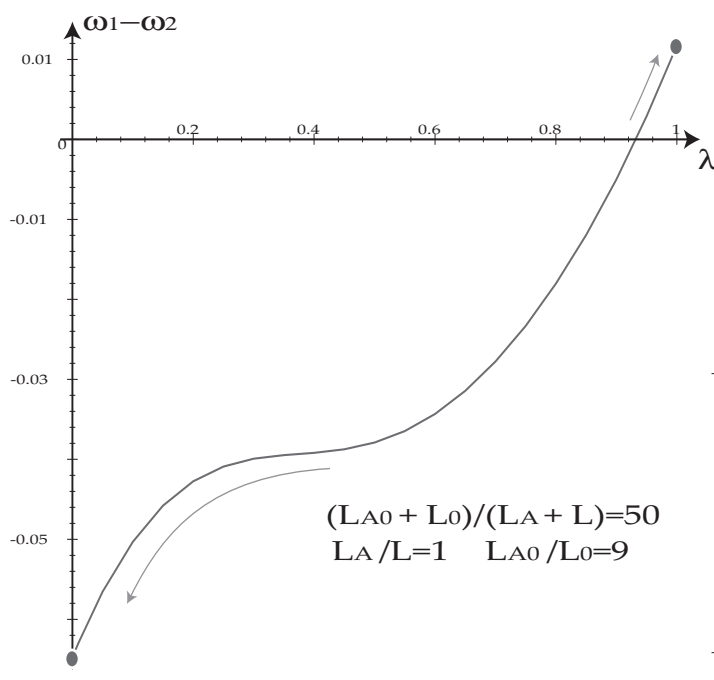

(a)

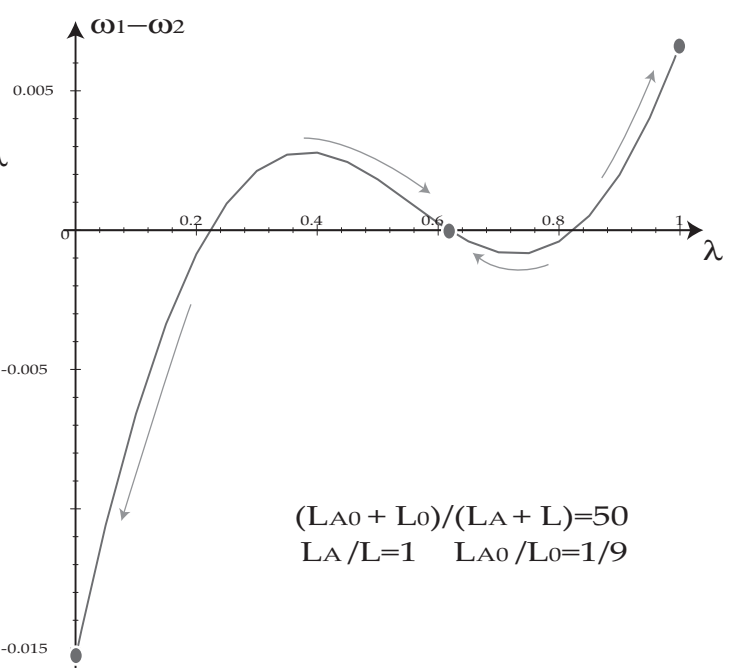

(b)

We observe the following patterns: when the home country has a relatively small manufacturing sector, the competition effect dominates, and manufacturing is more likely to concentrate in the interior region. On the other hand, when the home country hosts a relatively large manufacturing sector, agglomeration forces towards the border will be stronger.

In sum, our model suggests that the larger the domestic manufacturing share and the smaller the foreign one, the stronger will be tendency for domestic manufacturing to relocate towards the border region. Taken at face value, this result could be interpreted to imply that EU enlargement will favour the location of industry in regions proximate to the new accession countries, particularly in those sectors where direct import competition from accession countries is unlikely to be strong.

\section{Empirics}

\subsection{Market Potential and Regional Activity in the EU: Benchmark Regres- sions}

Our theoretical model shows that external market access can act as a force that shapes the internal spatial allocation of economic activity even if there are no differences in endowments. The relatively simple model of economic geography that we work with yields a rich set of predictions, featuring multiple equilibria, path dependency, and differential effects of market 
Figure 3: Internal Geography and Sectoral Specialisation of the Domestic Economy

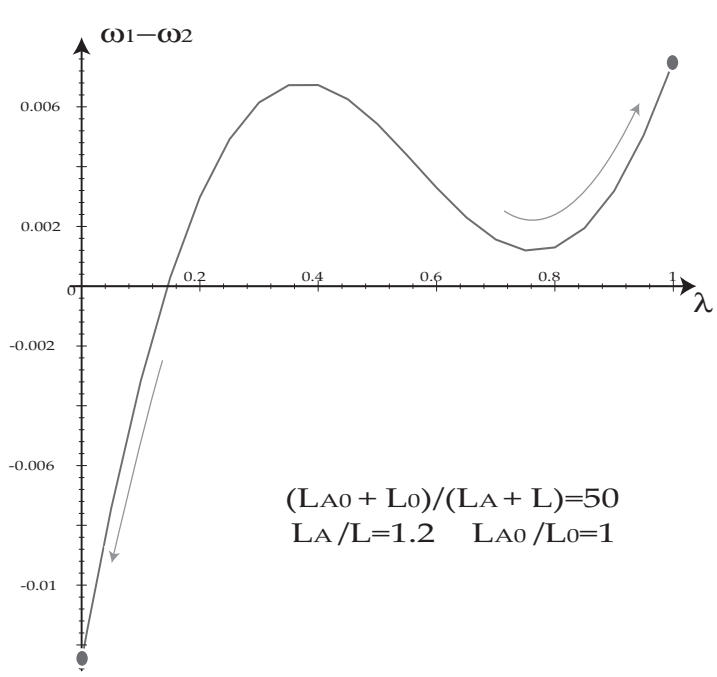

(a)

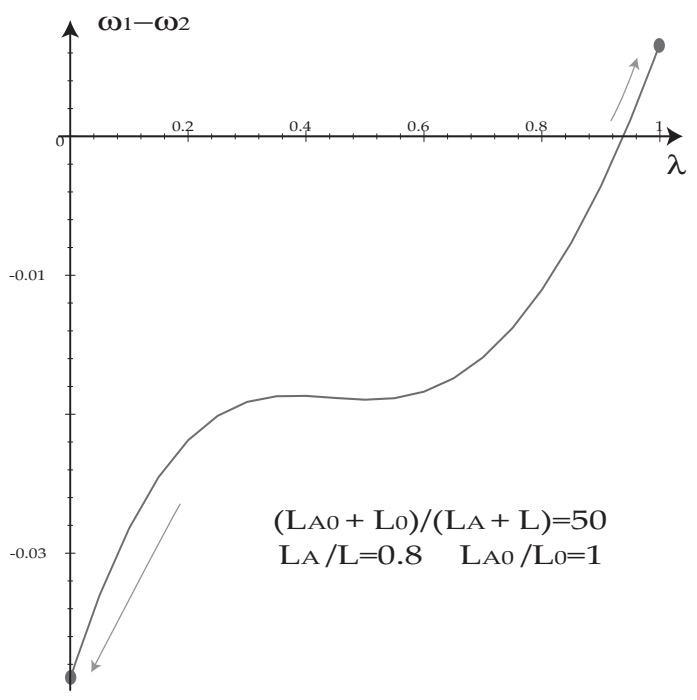

(b)

access dependent on sector composition and region sizes. In our empirical investigation, we abstract from most of the theoretical complexity and focus on the principal prediction of the model, that a change in external market access will change the internal distribution of activity. The question we ask is: given the estimated equilibrium relationship between market access and the location of activity, how is the change in market access implied by EU enlargement likely to alter the internal geography of the pre-enlargement EU?

We define market access using Harris's (1954) market potential function

$$
M_{i, J}=\sum_{j} Y_{i} / d_{i j}, \quad j \in J
$$

where $i$ and $j$ denote regions, $Y$ stands for economic mass, $d$ represents bilateral distance, and $J$ denotes the relevant set of trading regions. A region's economic mass is defined alternatively using GDP or sectoral employment. Drawing on the dataset of Schürmann and Talaat (2000), interregional distances are represented by estimated road-freight travel times between regional capitals. These estimates take account of road quality, border delays and legal constraints that affect the speed of road transport (see Appendix B for details on the data used).

The central element of our empirical exercise is to compute estimated market potentials $\hat{M}_{i}$ with different assumptions on what constitutes the relevant set of trading regions $J$. Since we are interested in the effects of EU enlargement on regional economies of incumbent member states, we compute $\hat{M}_{i}$ for regions in the EU15 assuming three different scenarios. In the first 
scenario, $J$ is defined as including only the EU-15 plus EFTA. This implies that, so far as economic location is concerned, European regions' market access is defined solely with respect to established Western European markets. Hence, geographical proximity to regions east of the pre-2004 eastern EU border is assumed to be economically irrelevant. In the second scenario, $J$ is defined as including in also the regions of the ten 2004 accession countries. We call this the EU-25 scenario. Estimated market potentials in the EU-25 scenario imply that proximity to regions outside of the post-2004 EU+EFTA borders is economically irrelevant. Finally, in what we call the EU-33 scenario, $J$ in addition includes the possible future accession countries Albania, Bosnia-Herzegovina, Bulgaria, Croatia, Macedonia, Romania, Serbia-Montenegro and Turkey.

Regional activity can be defined in various ways. We retain two activity measures, GDP per capita, and manufacturing employment (assuming that manufacturing is the most mobile sector).

The baseline regression model for GDP per capita is as follows:

$$
(G D P / P O P)_{i}=\beta_{0}+\beta_{1} \hat{M}_{i, J}+\beta_{2} \operatorname{Obj}_{1 D u m_{i}}+\vec{\gamma} \vec{X}+\epsilon_{i}, \quad \text { with } \quad J=E U 15+E F T A-i
$$

where $\hat{M}_{i, J}$ is the estimated market potential of region $i$ considering only EU15+EFTA partner

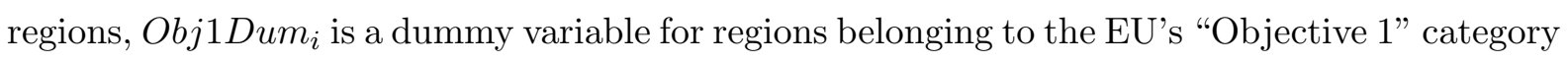
of economically lagging regions, and $\vec{X}$ is a set of country fixed effects. In order to avoid simultaneity problems, we have purged $\hat{M}_{i, J}$ of the region's own GDP.

Column 1 of Table 1 reports our estimation results for this specification. We find that the model fits the data well: 42 percent of within-country variation in per-capita GDP is explained by our market potential measure, and the RESET test suggests no misspecification. The point estimate on $\hat{M}_{i, J}$ is statistically significant and implies that a 10 percent increase in a region's market potential will increase its per-capita GDP by 1.5 percent.

We then estimated the same model, but replacing the dependent variable by the share of a region's population that is employed in the manufacturing sector $\left(M a n E m p / P_{0} p_{i}\right)$. The results are reported in column 2 of Table 1. We find that GDP-based market potential is considerably less successful in predicting employment shares than it was in predicting per-capita GDP: the explanatory power in terms of R-square has fallen significantly, and, more importantly, the RESET test indicates misspecification. This is in fact not surprising. Our model suggests that sectoral location may be affected unequally by proximity to different sectors, depending on whether co-agglomeration forces are positive or negative. Therefore, we have augmented the 
Table 1: Market Potential Regressions

\begin{tabular}{|l|c|c|c|}
\hline \multirow{2}{*}{ Regressors: } & Dependent var.: & GDPer capita & \multicolumn{2}{|c|}{ Manufacturing employment / Population } \\
\cline { 2 - 4 } & $(1)$ & $(2)$ & $(3)$ \\
\hline GDP Market Potential & $\begin{array}{l}0.145^{*} \\
(0.068)\end{array}$ & $\begin{array}{l}0.721^{*} \\
(0.181)\end{array}$ & $\begin{array}{c}-1.468 \\
(0.841)\end{array}$ \\
\hline Manufacturing Market & & & $2.676^{*}$ \\
Potential & & & $(0.816)$ \\
\hline Distribution Market & & & 0.714 \\
Potential & & & $(0.745)$ \\
\hline Financial Services Market & & & -1.104 \\
Potential & & $-0.285^{*}$ & $(0.693)$ \\
\hline Objective 1 region dummy & $-0.353^{*}$ & $(0.085)$ & $-0.302^{*}$ \\
& $(0.032)$ & Yes & Yes \\
\hline Country fixed effects & Yes & 192 & 192 \\
\hline Observations & 202 & 0.47 & 0.52 \\
\hline Total R-square & 0.61 & 0.25 & 0.31 \\
\hline Within R-square & 0.42 & $6.49^{*}$ & $4.25^{*}$ \\
\hline F statistic on fixed effects & $3.32^{*}$ & 0.02 & 0.14 \\
\hline RESET test, $p$-value & 0.75 & & \\
\hline
\end{tabular}

Notes: see text for variable definitions; all non-binary variables in logs; heteroskedasticityconsistent standard errors in parentheses; ${ }^{*}$ denotes statistical significance at $5 \%$ level 
manufacturing baseline specification to include three additional market potential variables: $(i)$ manufacturing market potential, for which we define $Y_{i}$ in (1) as manufacturing employment; (ii) distribution market potential, for which we define $Y_{i}$ in (1) as employment in distribution services; and (iii) financial services market potential, for which we define $Y_{i}$ in (1) as employment in financial services. ${ }^{10}$

Column 3 of Table 1 reports the results of the extended model for manufacturing. This model explains 31 percent of within-country variation in manufacturing employment shares, and the RESET test no longer suggests misspecification. The estimated coefficients are interesting: The effect of manufacturing market potential is strongly and significantly positive. This suggests that positive agglomeration forces dominate the competition effect. We also find a positive relationship between manufacturing employment and distribution market potential, although this effect is not statistically significant. Although they are not statistically significant either, the negative coefficients on GDP market potential and financial services market potential are suggestive of a pattern that sees manufacturing activities locating away from the main (urban) economic centres. ${ }^{11}$ The most striking aspect of our regression results for this model, however, is the size of the point estimates. The data suggest that the elasticities of manufacturing employment shares are larger than one (in absolute value) with respect to three of the four market potential measures in the model. We find, for example, that a 10 percent increase in manufacturing market potential (own-region effects not included) will raise a region's manufacturing employment share by roughly 27 percent. This finding is consistent with the "home-market effect" that characterises modern trade and geography models, according to which differences in market access translate into larger than proportional differences is sectoral production shares.

\subsection{EU Enlargement and Objective 1 Regions: Simulations}

\subsubsection{Regional Per Capita GDP}

Our simulation strategy is straightforward. We take the coefficients estimated for the benchmark regressions (models 1 and 3 of Table 1), recalculate the market potential variable $\hat{M}_{i}$ by including the ten 2004 accession countries, and predict per capita GDPs and manufacturing employment shares in incumbent EU regions on this basis (the EU-25 scenario). These predicted values are

\footnotetext{
${ }^{10}$ To avoid simultaneity, we dropped own-region employment in the computation of manufacturing market potential. Own-region employment was, however, considered in the construction of distribution and financial services market potential measures. The number of observations in the employment regressions is smaller than in the GDP regressions, because we lack the relevant data for the regions of former East Germany.

${ }^{11}$ This is consistent with the finding of Brülhart and Traeger (2003) that, since the 1970s, the share of EU manufacturing jobs in peripheral regions has been increasing.
} 
then compared to fitted values from the benchmark regressions.

Table 2: Regional GDPs

\begin{tabular}{|c|c|c|c|c|c|c|}
\hline Country & Region & NUTS & $\begin{array}{l}\text { GDP Market } \\
\text { Potential }{ }^{2}\end{array}$ & $\begin{array}{c}\text { GDP } \\
\text { per capita }{ }^{3}\end{array}$ & \begin{tabular}{|c|}
$\%$-age \\
$\Delta G D P$ \\
$E U-25^{4}$ \\
\end{tabular} & $\begin{array}{c}\% \text {-age } \\
\Delta G D P, \\
E U-33^{4}\end{array}$ \\
\hline Austria & Burgenland & AT11 & 7,468 & 13.98 & 2.116 & 2.525 \\
\hline \multirow[t]{9}{*}{ Germany } & Brandenburg & DE4 & 9,093 & 14.20 & 1.049 & 1.254 \\
\hline & $\begin{array}{l}\text { Mecklenburg-Western } \\
\text { Pomerania }\end{array}$ & DE8 & 8,259 & 12.94 & 0.968 & 1.175 \\
\hline & Chemnitz & DED1 & 9,996 & 11.91 & 1.022 & 1.230 \\
\hline & Dresden & DED2 & 9,126 & 13.93 & 1.187 & 1.408 \\
\hline & Leipzig & DED3 & 10,192 & 14.92 & 0.967 & 1.164 \\
\hline & Dessau & DEE1 & 10,106 & 11.92 & 0.911 & 1.101 \\
\hline & Halle & DEE2 & 10,658 & 13.84 & 0.884 & 1.073 \\
\hline & Magdeburg & DEE3 & 10,193 & 12.15 & 0.839 & 1.021 \\
\hline & Thuringia & DEG & 10,885 & 12.81 & 0.839 & 1.028 \\
\hline \multirow[t]{2}{*}{ Finland } & Eastern Finland & FI13 & 2,941 & 14.54 & 1.255 & 1.597 \\
\hline & Northern Finland & FI15 & 2,645 & 16.64 & 1.231 & 1.579 \\
\hline \multirow[t]{13}{*}{ Greece } & $\begin{array}{l}\text { East Macedonia and } \\
\text { Thrace }\end{array}$ & GR11 & 2,737 & 11.54 & 1.396 & 2.773 \\
\hline & Central Macedonia & GR12 & 3,180 & 12.67 & 1.389 & 2.568 \\
\hline & West Macedonia & GR13 & 2,993 & 11.66 & 1.324 & 2.372 \\
\hline & Thessalia & GR14 & 3,134 & 11.85 & 1.254 & 2.255 \\
\hline & Epirus & GR21 & 2,876 & 8.22 & 1.247 & 2.157 \\
\hline & Ionian Islands & GR22 & 2,690 & 11.59 & 1.199 & 1.994 \\
\hline & Western Greece & GR23 & 3,225 & 10.88 & 1.056 & 1.785 \\
\hline & Continental Greece & GR24 & 3,266 & 12.39 & 1.126 & 1.976 \\
\hline & Peloponnese & GR25 & 3,223 & 11.04 & 1.049 & 1.786 \\
\hline & Attica & GR3 & 5,017 & 14.53 & 1.179 & 2.034 \\
\hline & North Aegean & GR41 & 2,180 & 9.81 & 1.225 & 1.999 \\
\hline & South Aegean & GR42 & 2,221 & 14.16 & 1.196 & 1.915 \\
\hline & Crete & GR43 & 2,324 & 13.67 & 1.211 & 1.933 \\
\hline Ireland & $\begin{array}{l}\text { Border, Midlands, } \\
\text { West }\end{array}$ & IE01 & 4,819 & 14.44 & 0.641 & 0.853 \\
\hline
\end{tabular}

The results for regional per capita GDP are reported in Table 2. Given the focus of this study, we report individual results for peripheral regions only, where peripherality is understood to mean Objective 1 status in the EU's regional policy. The second-last column of Table 2 lists percentage differences in predicted per capita GDPs. Given the simple linear functional form we have imposed, the changes are necessarily positive. On average, our simulations suggest that Objective 1 regions' incomes rise by 0.93 percent while those of non-Objective 1 regions rise by 0.65 percent (last two rows of Table 2). Although these magnitudes may appear small, they are likely overestimates, since our simulation scenario implies a regime switch from infinite trade costs at the EU border to trade costs that are as low as those that applied to intra-EU trade in the late 1990s. We therefore deem the relative information implied in our simulations 
Table 2 contd.

\begin{tabular}{|c|c|c|c|c|c|c|}
\hline \multirow[t]{6}{*}{ Italy } & Campania & IT8 & 7,260 & 12.61 & 0.852 & 1.148 \\
\hline & Apulia & IT91 & 6,154 & 13.65 & 0.908 & 1.236 \\
\hline & Basilicata & IT92 & 5,805 & 13.33 & 0.836 & 1.133 \\
\hline & Calabria & IT93 & 4,826 & 11.38 & 0.919 & 1.257 \\
\hline & Sicily & ITA & 4,360 & 12.61 & 1.005 & 1.375 \\
\hline & Sardinia & ITB & 4,512 & 13.93 & 0.881 & 1.189 \\
\hline \multirow[t]{4}{*}{ Portugal } & North & PT11 & 5,247 & 12.45 & 0.633 & 0.853 \\
\hline & Centre & PT12 & 5,048 & 12.20 & 0.603 & 0.813 \\
\hline & Alentejo & PT14 & 4,485 & 12.43 & 0.609 & 0.826 \\
\hline & Algarve & PT15 & 4,141 & 14.33 & 0.652 & 0.886 \\
\hline \multirow[t]{8}{*}{ Spain } & Galicia & ES11 & 5,006 & 12.31 & 0.637 & 0.858 \\
\hline & Asturias & ES12 & 5,643 & 14.63 & 0.601 & 0.807 \\
\hline & Castile Leon & ES41 & 6,092 & 14.82 & 0.562 & 0.754 \\
\hline & Castile La Mancha & ES42 & 5,852 & 12.90 & 0.557 & 0.752 \\
\hline & Extremadura & ES43 & 5,111 & 10.55 & 0.584 & 0.790 \\
\hline & Valencia & ES52 & 6,396 & 14.67 & 0.628 & 0.845 \\
\hline & Andalusia & ES61 & 4,938 & 11.25 & 0.668 & 0.905 \\
\hline & Murcia & ES62 & 5,607 & 13.12 & 0.613 & 0.827 \\
\hline \multirow[t]{2}{*}{ Sweden } & Central Norrland & SE07 & 3,442 & 19.53 & 1.071 & 1.359 \\
\hline & Upper Norrland & SE08 & 2,921 & 19.00 & 1.128 & 1.439 \\
\hline \multirow[t]{4}{*}{ UK } & Merseyside & UKD5 & 12,212 & 14.50 & 0.388 & 0.510 \\
\hline & South Yorkshire & UKE3 & 12,399 & 14.61 & 0.366 & 0.480 \\
\hline & Cornwall & UKK3 & 7,350 & 14.45 & 0.530 & 0.698 \\
\hline & West Wales & UKL1 & 9,201 & 14.33 & 0.461 & 0.605 \\
\hline \multicolumn{3}{|c|}{ Average of Objective 1 regions (50 regions) } & 5,789 & 13.24 & 0.929 & 1.338 \\
\hline \multicolumn{3}{|c|}{ Average of non-Obj. 1 regions (152 regions) } & 11,253 & 20.38 & 0.653 & 0.831 \\
\hline
\end{tabular}

1 Eurostat's region codes (Nomenclature of Territorial Units for Statistics)

2 including regions' own GDP, considering only EU+EFTA (see text for full definition)

31998 purchasing-power parity data

${ }^{4}$ projected percentage changes in per-capita GDPs with EU-25 and EU-33 enlargement scenarios 
more informative than absolute magnitudes. Among Objective 1 regions, we indeed observe considerable variance in the magnitude of estimated effects. Our projected income changes range from 0.37 percent (South Yorkshire) to 2.12 percent (Burgenland). The maximum effect is thus almost six times larger than the minimum. Our adopted linear specification implies that the effect of enlargement is stronger the closer a region is to the accession countries (in terms of road freight travel time), and the less close it is to alternative large centres of economic activity. ${ }^{12}$ It is the latter factor that is key to our findings that the effect for Austria's Burgenland region is more than twice that for most East German regions, and that the effect for the West of Ireland is considerably larger than that for all English and Welsh regions.

In a second simulation, we recomputed market potentials to include eight additional countries that are potential candidates for a next EU enlargement (the EU-33 scenario). Simulated income changes relative to the EU-only benchmark are reported in the right-most column of Table 2. With these simulations, we find that the income effects range from 0.48 percent (South Yorkshire) to 2.77 percent (East Macedonia and Thrace). Given that all of the additional countries considered in this simulation are located in the Balkans, it is of course not surprising to find that the strongest effects of such a future enlargment would be felt by Greek regions. Indeed, according to our simulations, a future Balkans enlargement would add an additional 0.83 percent to the per capita GDP of the average Greek region, while it would boost the regional income of the average UK Objective 1 region by a mere 0.14 percent.

From regional policy perspective, it might be of interest how the simulated regional income effects correlate with pre-enlargement relative incomes of Objective 1 regions. The simple correlation coefficient between 1998 real purchasing-power parity per capita GDP and our simulated EU-25 effect (i.e. between the second and third data columns in Table 2) is -0.07, which is statistically insignificant. The same correlation but with the EU-33 simulated effects is -0.24 , which is statistically significant at the 10 percent level. Note finally that the average GDP effect in the EU-33 scenario is 60 percent larger for Objective 1 regions than for non-Objective 1 regions (final two rows of Table 2). Our simulations therefore suggest that the market-access effects of the 2004 enlargement will neither exacerbate nor reduce income inequalities among Objective 1 regions, but that a future Balkans enlargements could reduce these inequalities, mainly by boosting income in Greece.

\footnotetext{
${ }^{12}$ We experimented with nonlinear specifications of our benchmark regressions but did not find them to add any explanatory power.
} 


\subsubsection{Regional Manufacturing Employment}

In a second set of simulations we take the coefficients from our benchmark regressions on manufacturing employment (Table 1, model 3), and apply them to EU-25 market potentials, so as to obtain predicted post-enlargement employment shares. ${ }^{13}$ The results are shown in Table 3.

\section{Table 3: Regional Manufacturing Employment}

\begin{tabular}{|c|c|c|c|}
\hline Country & Region & $\begin{array}{l}\text { Manufact. } \\
\text { Employmt / } \\
\text { Population }\end{array}$ & $\begin{array}{c}\% \text { o-age } \\
\Delta \text { man.empl., } \\
\text { EU-25 }\end{array}$ \\
\hline Austria & Burgenland & 5.07 & 86.9 \\
\hline \multirow[t]{9}{*}{ Germany } & Brandenburg & n.a. & 41.5 \\
\hline & $\begin{array}{l}\text { Mecklenburg-Western } \\
\text { Pomerania }\end{array}$ & n.a. & 37.7 \\
\hline & Chemnitz & n.a. & 38.1 \\
\hline & Dresden & n.a. & 46.5 \\
\hline & Leipzig & n.a. & 37.7 \\
\hline & Dessau & n.a. & 35.9 \\
\hline & Halle & n.a. & 33.8 \\
\hline & Magdeburg & n.a. & 31.5 \\
\hline & Thuringia & n.a. & 29.7 \\
\hline \multirow[t]{2}{*}{ Finland } & Eastern Finland & 6.44 & 40.5 \\
\hline & Northern Finland & 7.87 & 40.7 \\
\hline \multirow[t]{13}{*}{ Greece } & $\begin{array}{l}\text { East Macedonia and } \\
\text { Thrace }\end{array}$ & 5.70 & 48.3 \\
\hline & Central Macedonia & 7.50 & 48.2 \\
\hline & West Macedonia & 8.26 & 44.8 \\
\hline & Thessalia & 5.12 & 41.4 \\
\hline & Epirus & 3.77 & 42.7 \\
\hline & Ionian Islands & 2.48 & 41.5 \\
\hline & Western Greece & 2.72 & 35.3 \\
\hline & Continental Greece & 5.73 & 36.0 \\
\hline & Peloponnese & 3.28 & 33.9 \\
\hline & Attica & 8.23 & 40.9 \\
\hline & North Aegean & 3.81 & 42.6 \\
\hline & South Aegean & 4.08 & 41.2 \\
\hline & Crete & 3.03 & 40.8 \\
\hline Ireland & Border, Midlands, West & 9.38 & 23.1 \\
\hline
\end{tabular}

As expected, given the large coefficients obtained in the benchmark regression, the magnitudes of the simulated effects are substantial. We predict increases in the share of regional populations employed in manufacturing that range from 12.4 percent (South Yorkshire) to to 86.9 percent (Burgenland). Here too, we of course have to interpret absolute magnitudes with caution. Nonetheless, it should be noted that the fact that all estimated effects are positive is

\footnotetext{
${ }^{13}$ Due to lack of sectoral data for non-EU-25 countries, we cannot carry out EU-33 simulations on employment shares.
} 
Table 3 contd.

\begin{tabular}{|c|c|c|c|}
\hline \multirow[t]{6}{*}{ Italy } & Campania & 3.19 & 30.9 \\
\hline & Apulia & 3.84 & 32.8 \\
\hline & Basilicata & 4.10 & 31.1 \\
\hline & Calabria & 1.74 & 33.3 \\
\hline & Sicily & 2.35 & 35.1 \\
\hline & Sardinia & 3.43 & 31.2 \\
\hline \multirow[t]{4}{*}{ Portugal } & North & 12.86 & 21.7 \\
\hline & Centre & 8.01 & 19.2 \\
\hline & Alentejo & 3.29 & 20.2 \\
\hline & Algarve & 2.60 & 21.8 \\
\hline \multirow[t]{8}{*}{ Spain } & Galicia & 6.54 & 20.1 \\
\hline & Asturias & 6.94 & 19.5 \\
\hline & Castile Leon & 6.63 & 18.1 \\
\hline & Castile La Mancha & 7.58 & 18.3 \\
\hline & Extremadura & 2.69 & 19.2 \\
\hline & Valencia & 10.40 & 20.7 \\
\hline & Andalusia & 3.87 & 21.9 \\
\hline & Murcia & 6.97 & 19.5 \\
\hline \multirow[t]{2}{*}{ Sweden } & Central Norrland & 8.47 & 38.3 \\
\hline & Upper Norrland & 8.22 & 38.4 \\
\hline \multirow[t]{4}{*}{ UK } & Merseyside & 4.93 & 13.1 \\
\hline & South Yorkshire & 7.73 & 12.4 \\
\hline & Cornwall & 5.35 & 19.2 \\
\hline & West Wales & 5.13 & 16.5 \\
\hline \multicolumn{2}{|c|}{$\begin{array}{l}\text { Average of Objective } 1 \text { regions } \\
\text { (50 regions) }\end{array}$} & 5.59 & 32.7 \\
\hline \multicolumn{2}{|c|}{$\begin{array}{l}\text { Average of non-Objective } 1 \text { regions } \\
\text { (152 regions) }\end{array}$} & 8.76 & 23.4 \\
\hline
\end{tabular}

${ }^{1}$ projected percentage changes in (manufacturing employment / population) with EU-25 enlargement scenario 
not a necessary result of our specification here, since negative changes would in principle be possible. The market-access effect of EU enlargement on manufacturing employment in Objective 1 regions thus appears to be unambiguously positive.

The relative pattern of manufacturing effects resembles that found for regional incomes quite closely: regions that are proximate to the accession countries and relatively far from economic centres of the pre-enlargement EU benefit relatively more. Variations in the geographical distribution of manufacturing and service sectors across the regions of accession countries do not appear to be large enough to affect relative effects on incumbent EU regions significantly.

Finally, we again find that the market access effects of enlargement on average benefit Objective 1 regions more than non-Objective 1 regions. The simulated increase in manufacturing employment is 32.7 percent for the average Objective 1 region and 23.4 percent for the average non-Objective 1 region (last two rows of Table 3).

\section{Conclusions}

We have explored the implications of changing market access in an enlarged EU, focussing on peripheral regions of incumbent member states. A three-region version of Krugman's (1991) core-periphery model predicts that, for most parameter configurations, external liberalisation favours the concentration of the mobile sector in the domestic region that is close to the outside country (the "border region"). Our empirical simulations suggest that the economic impacts of enlargement are indeed likely to be significantly different depending on regions' geographic location relative to the new member states. We find that the effect on regional per-capita income is six times larger in the most affected Objective 1 region (Burgenland, Austria) than in the least affected one (South Yorkshire, UK). In terms of manufacturing employment, this difference rises to a factor seven. We also find that the distribution of market-access related gains from the 2004 enlargement will not reduce inequality among current Objective 1 regions; but that a possible future Balkans enlargement would have such an effect, mainly by improving market access conditions for Greece. 


\section{References}

Baldwin R.E., J.F. Francois, R. Portes, 1997, "The Costs and Benefits of Eastern Enlargement: The Impact on the EU and Central Europe", Economic Policy, 24: 125176.

Behrens, K., C. Gaigne, G.I.P. Ottaviano and J.F. Thisse, 2003, "Inter-Regional and International Trade: Seventy Years after Ohlin", CEPR Discussion Paper, No. 4065.

Bröcker, J., 1998, "How Would an EU Membership of the Visegrad Countries Affect Europe's Economic Geography? Annals of Regional Science, 32: 91-114.

Brülhart, M. And R. Traeger, 2003, "An Account of Geographic Concentration Patterns in Europe", Mimeo, University of Lausanne.

Forslid, R., J.I. HaAland, K.H. Midelfart-Knarvik and O. Maestad, 2002, "Integration and Transition: Scenarios for the Location of Production and Trade in Europe", Economics of Transition, 10(1): 93-117.

Head, K. and T. Mayer, 2002, "Illusory Border Effects: How Far is an Economy from Itself?", CEPII Discussion Paper, 2002-1, Paris.

Krugman, P., 1991, "Increasing Returns and Economic Geography",Journal of Political Economy, 99(3): 483-499.

Krugman, P. and R. Livas Elizondo, 1996, "Trade Policy and the Third World Metropolis", Journal of Development Economics, 49(1): 137-150.

Monfort, P. And R. Nicolini, 2000, "Regional Convergence and International Integration", Journal of Urban Economics, 48(2): 286-306.

Niebuhr, A., 2003, "Market Potential and Regional Disparities in Europe", Mimeo, Hamburg Institute of International Economics.

Paluzie, E., 2001, "Trade Policies and Regional Inequalities", Papers in Regional Science, 80(1): $67-85$.

Schürmann, C. and A. Talaat, 2000, "Towards a European Peripherality Index", Report for DGXVI Regional Policy of the European Commission, University of Dortmund. 


\section{A A Three-Region Core-Periphery Model}

This appendix spells out our three-region version of Krugman's (1991) geography model.

\section{A.1 Consumers and Price Indices}

All consumers share the same Cobb-Douglas utility function:

$$
U=M^{\mu} A^{1-\mu} \text {, with } 0<\mu<1 \text {. }
$$

$M$ is a composite index of the consumption of the manufactured good, $A$ denotes consumption of the agricultural good. A share $\mu$ of expenditures goes to manufactured goods, and $1-\mu$ to the agricultural good. The composite index $M$ is defined by the following CES function:

$$
M=\left[\sum_{i=1}^{n} c_{i}^{\frac{\sigma-1}{\sigma}}\right]^{\frac{\sigma}{\sigma-1}}
$$

where $c_{i}$ represents consumption of a variety $i$ of the manufactured good, and $\sigma$ is the elasticity of substitution between two varieties $(\sigma>1)$. Given income $Y$, each consumer maximises utility under the budget constraint $Y=A p_{A}+\sum_{i=1}^{n} c_{i} p_{i}$. Using (3) and (4), we can derive the following demand function, representing demand emanating from consumers of region $s$, addressed to a producer $i$ located in region $r$ :

$$
c_{i, r s}=\frac{p_{i r s}^{-\sigma}}{\sum_{r=0}^{R} \sum_{i=1}^{n_{r}}\left(p_{i r s}\right)^{1-\sigma}} \mu Y_{s}, \quad r, s=0,1,2 .
$$

Equation (5) contains the spatial framework: there are $R=3$ regions, each of them producing $n_{r}$ varieties of the manufacturing good. Iceberg trade costs imply that the price of each variety $i$ produced in $r$ and sold in $s$ contains the mill price and the trade cost: $p_{i r s}=p_{r} T_{r s}$ (because of the symmetry of all varieties produced in the same region, we henceforth omit the variety subscript $i$ ). We use $T_{r s}$ as a general expression which represents either $T_{12}, T_{01}$ or $T_{02}$, assuming that the trade cost between two regions is identical for both directions of trade flows, and that $T_{r r}=1$. Using (4) and (5), we are thus able to derive the following industrial price index for each region $s$ :

$$
P_{s}=\left[\sum_{r=0}^{R} n_{r}\left(p_{r} T_{r s}\right)^{1-\sigma}\right]^{\frac{1}{1-\sigma}}
$$

Individual demand (5) can now be written as:

$$
c_{r s}=\frac{\left(p_{r} T_{r s}\right)^{-\sigma}}{P_{s}^{1-\sigma}} \mu Y_{s} \quad r, s=0,1,2
$$

\section{A.2 Producers}

Manufactured goods are produced in a monopolistically competitive industry. Each producer has the same production function, expressed in terms of manufacturing labour: $l=\alpha+\beta q$, where $l$ is the total cost, in terms of labour, of producing $q$ units. $l$ contains a fixed cost $\alpha$ and a 
marginal cost $\beta$ per additional unit produced. As usual in the Dixit and Stiglitz (1977) model, we obtain constant mark-up equations for profit-maximising firms:

$$
p_{r}=\left(\frac{\sigma}{\sigma-1}\right) w_{r} \beta
$$

where $p_{r}$ is the price of a variety produced in $r$ and $w_{r}$ is the manufacturing wage in region $r$. The equilibrium output of a firm producing in region $r$ is derived from the free entry condition:

$$
q_{r}^{*}=\frac{\alpha(\sigma-1)}{\beta},
$$

and equilibrium in each region's labour market allows us to obtain the equilibrium number of firms in each region:

$$
n_{r}=\frac{L_{r}}{\alpha \sigma},
$$

where $L_{r}$ is the total number of manufacturing workers in region $r$.

\section{A.3 Short-Rum Equilibrium}

We can derive, for a given distribution of labour between regions 1 and 2 , the value of $w_{r}$ that satisfies equations (7), (8), (9), (10) and the equilibrium condition on the goods market. The manufacturing wage equation for each region $r$ is thus:

$$
w_{r}=\frac{1}{\beta}\left(\frac{\sigma-1}{\sigma}\right)\left[\frac{\mu \beta}{\alpha(\sigma-1)}\left(\sum_{j=0}^{R} Y_{j} P_{j}^{\sigma-1} T_{j r}^{1-\sigma}\right)\right]^{1 / \sigma}
$$

with $Y_{r}=w_{r} L_{r}+w_{A r} L_{A r}$, and $w_{A r}$ equal to 1 because we chose it as a numéraire. Equation (11) is a typical wage equation in new economic geography models. It implies that the larger the number of consumers and the smaller the number of competitors in regions with low trade costs to $r$, the higher the nominal wage that a firm producing in $r$ can pay: indeed, the nominal wage in region $r$ tends to be higher if incomes in other regions with low trade costs to $r$ are high. On the other hand, $w_{r}$ tends to be lower if other regions with low transaction costs to $r$ contain a large number of firms (the region's industrial price index $P_{j}^{\sigma-1}$ may be regarded as an index of concentration).

We are now able to characterize entirely the equilibrium variables in our three-region setting, for a given spatial distribution of workers. Regional incomes are:

$$
\begin{aligned}
& Y_{1}=w_{1} \lambda+L_{A 1}, \\
& Y_{2}=w_{2}(1-\lambda)+L_{A 2}, \\
& Y_{0}=w_{0} L_{0}+L_{A 0} .
\end{aligned}
$$

Nominal wages are the solution of the following system, where $P$ and $Y$ have to be substituted 
for as functions of wages using (6), (8), (10) and $Y_{r}=w_{r} L_{r}+L_{A r} w_{A r}$ :

$$
\begin{aligned}
& w_{1}=\frac{1}{\beta}\left(\frac{\sigma-1}{\sigma}\right)\left[\frac{\mu \beta}{\alpha(\sigma-1)}\left(Y_{0} P_{0}^{\sigma-1} T_{01}^{1-\sigma}+Y_{1} P_{1}^{\sigma-1}+Y_{2} P_{2}^{\sigma-1} T_{12}^{1-\sigma}\right)\right]^{1 / \sigma}, \\
& w_{2}=\frac{1}{\beta}\left(\frac{\sigma-1}{\sigma}\right)\left[\frac{\mu \beta}{\alpha(\sigma-1)}\left(Y_{0} P_{0}^{\sigma-1} T_{02}^{1-\sigma}+Y_{1} P_{1}^{\sigma-1} T_{12}^{1-\sigma}+Y_{2} P_{2}^{\sigma-1}\right)\right]^{1 / \sigma}, \\
& w_{0}=\frac{1}{\beta}\left(\frac{\sigma-1}{\sigma}\right)\left[\frac{\mu \beta}{\alpha(\sigma-1)}\left(Y_{0} P_{0}^{\sigma-1}+Y_{1} P_{1}^{\sigma-1} T_{01}^{1-\sigma}+Y_{2} P_{2}^{\sigma-1} T_{02}^{1-\sigma}\right)\right]^{1 / \sigma} .
\end{aligned}
$$

The industrial price indices are then given by:

$$
\begin{aligned}
& P_{1}=\left(\frac{\sigma \beta}{\sigma-1}\right)\left(\frac{1}{\alpha \sigma}\right)^{1 / 1-\sigma}\left[L_{0}\left(w_{0} T_{0}\right)^{1-\sigma}+\lambda w_{1}^{1-\sigma}+(1-\lambda)\left(w_{2} T_{12}\right)^{1-\sigma}\right]^{1 / 1-\sigma} \\
& P_{2}=\left(\frac{\sigma \beta}{\sigma-1}\right)\left(\frac{1}{\alpha \sigma}\right)^{1 / 1-\sigma}\left[L_{0}\left(w_{0} T_{0}\right)^{1-\sigma}+\lambda\left(w_{1} T_{12}\right)^{1-\sigma}+(1-\lambda) w_{2}^{1-\sigma}\right]^{1 / 1-\sigma} \\
& P_{0}=\left(\frac{\sigma \beta}{\sigma-1}\right)\left(\frac{1}{\alpha \sigma}\right)^{1 / 1-\sigma}\left[L_{0} w_{0}^{1-\sigma}+\lambda\left(w_{1} T_{0}\right)^{1-\sigma}+(1-\lambda)\left(w_{2} T_{0}\right)^{1-\sigma}\right]^{1 / 1-\sigma}
\end{aligned}
$$

We finally derive the real wage of each domestic region, which is made of the nominal wage deflated by the price index:

$$
\begin{aligned}
& \omega_{1}=\frac{w_{1}}{P_{1}^{\mu}}, \\
& \omega_{2}=\frac{w_{2}}{P_{2}^{\mu}} .
\end{aligned}
$$

\section{A.4 Long-Run Equilibrium}

In the long run, industrial workers are mobile: they move to the region with the highest real wage, according to the following law of motion:

$$
\frac{d \lambda}{d t}=\left\{\begin{array}{cl}
\Delta \omega & \text { if } \quad 0<\lambda<1 \\
\min \{0, \Delta \omega\} & \text { if } \quad \lambda=1 \\
\max \{0, \Delta \omega\} & \text { if } \quad \lambda=0
\end{array},\right.
$$

$\Delta \omega$ being the real wage differential.

We are interested in identifying the spatial equilibria of the model, i.e. the distributions of workers for which no worker will earn a higher real wage by changing location. The equilibrium distributions of the workforce consist of the values of $(\lambda, 1-\lambda)$ for which either $\omega_{1}-\omega_{2}=$ 0 and $\lambda \in(0,1)$, or $\omega_{1}-\omega_{2} \geq 0$ and $\lambda=1$, or $\omega_{1}-\omega_{2} \leq 0$ and $\lambda=0$.

As is typical in Krugman's core-periphery framework, $\omega_{1}-\omega_{2}$ is not a simple function of $\lambda$ : we are unable to determine the parameter values that accommodate spatial equilibria analytically. We therefore use numerical simulations in order to examine real wage differentials and their implied locational structures.

The equilibrium spatial distribution of the IRS sector inside the domestic country depends on the interaction of agglomeration and dispersion forces appearing in the equations we derived above. On the one hand, agglomeration forces arise through the fact that firms and consumers are interested in locating in the same region because of cost and demand externalities: in 
equations (15) and (16), a large number of consumers in a region $r$ or in nearby regions represents high local expenditure, allowing firms to pay higher wages, and thus attracting more firms. The cost externality appears in equations (18), (19) and (20): a high number of firms implies a large number of locally produced varieties, a lower price index and thus more immigrant consumers.

On the other hand, a dispersion force arises through fiercer competition on goods and factor markets when industrial activity is concentrated: equations (15) and (16) imply that the nominal wage of a region diminishes with an increase in competition. This effect pushes firms to relocate towards the interior region in order to benefit from weaker competitive pressures.

\section{B Data}

\section{B.1 Interregional Road Freight Travel Times}

Our estimated interregional effective distances are based on the Schürmann-Talaat (2000) dataset for NUTS 2 regions. Effective (i.e. economically relevant) distances are represented by road freight travel times in hours, which are in turn obtained by multiplying geographic road distances with estimated average travel speeds in $\mathrm{km} / \mathrm{h}$. Estimated travel speeds are a function of road categories, border delays, ferry port delays, statutory speed limits and statutory rest periods for drivers (for details, see Schürmann and Talaat (2000)).

The Schürmann-Talaat estimates for intra-regional travel times are based on the assumption that average intra-regional trip length is $10 \mathrm{~km}$ everywhere. Taking account of unequal region sizes, we assume instead that intra-regional distances can be approximated as a proportion of the radius of a circle whose area represents that of the region (see Head and Mayer, 2002, for a discussion of this and alternative intra-region distance estimations). Where our market potential variables included own-region components, we set that proportion to $1 / 3$ and assume average intra-regional travel speeds to be $30 \mathrm{~km} / \mathrm{h}$, so that $\widehat{d}_{i i}=2 * 0.33 * \sqrt{\frac{\text { area }_{i}}{\pi}}$.

Estimated intra-region travel times for the EU and CEEC regions range from 5 minutes (Brussels) to 2 hours 26 minutes (Övre Norrland, Sweden), and estimated inter-region travel times range from 34 minutes (Brussels - Brabant) to 113 hours (South Aegean, Greece - Northern Norway).

\section{B.2 Regional GDP and Employment}

For GDPs of NUTS 2 regions, we use Eurostat's data for 1998, based on purchasing-power parity exchange rates. For the EU, EFTA and CEEC regions (2004 accession countries), these GDPs range from EUR 0.6 bn (Åland, Finland) to EUR 335 bn (Ile de France). The market potential indices for the EU-33 sample furthermore incorporate country-level GDPs for Albania, Bosnia-Herzegovina, Bulgaria, Croatia, Macedonia, Romania, Turkey and Serbia-Montenegro.

Sectoral employment data for 1998, covering manufacturing, distribution services and financial services in NUTS 2 regions of EU15 countries plus Norway and Switzerland, are taken from the regional database compiled by Cambridge Econometrics. Corresponding data have been obtained from the Vienna Institute for International Economic Studies (WIIW) and from the Austrian Institute of Economic Research (WIFO) for five CEECs (Czech Republic, Hungary, Poland, Slovenia and Slovakia). Hence, our "EU-25" scenario of Table (3) does not incorporate data for Cyprus, Estonia, Latvia, Lithuania and Malta. 